\title{
The step-up protocol increases clinical pregnancy rates compared with the step-down in patients with unexplained infertility. A randomized controlled trial
}

\author{
Ana Robles ${ }^{1}$, Sonia Gayete-Lafuente ${ }^{1}$, Maria Prat ${ }^{1}$, Mireia Gonzalez-Comadran ${ }^{1}$, Miguel Ángel Checa ${ }^{1}$ \\ ${ }^{1}$ Reproductive Endocrinology Unit. Department of Obstetrics and Gynecology. Hospital del Mar de Barcelona. \\ Universitat Autònoma de Barcelona (UAB), Barcelona, Spain
}

\begin{abstract}
Objective: Unexplained infertility is a relevant indication for controlled ovarian stimulation associated to intrauterine insemination. The "step-up" and "step-down" gonadotropin-based protocols were designed to reduce multiple pregnancy and ovarian hyperstimulation syndrome in polycystic ovary syndrome patients, but there is no related evidence in normoovulatory women undergoing intrauterine insemination. Our aim was to compare the efficacy and safety of both protocols with intrauterine insemination in unexplained infertility patients.
\end{abstract}

Methods: Randomized clinical trial including 145 women with unexplained infertility randomly following the step-up $(n=73)$ or step-down $(n=72)$ protocol. In the stepup group, patients started on day 3 of a spontaneous cycle administrating recombinant FSH 75IU sc/day, increasing it to $150 \mathrm{IU}$ if no response after 7 days. In the step-down, patients started administrating 150IU sc/day, constantly decreasing it to 75IU after 5 days. Recombinant hCG was administered when a follicle reached $\geq 18 \mathrm{~mm}$ diameter.

Results: Clinical pregnancy rate was higher in the stepup group than in the step-down $(20.5 \%$ vs. $8.3 \% ; p=0.037)$. Significant differences between step-up and step-down protocols were found regarding days of $\mathrm{rFSH}$ administration $(8.83 \pm 4.01 \%$ vs. $7.42 \pm 2.18 \% ; p=0.001)$ and cancellation rate due to hyper response ( $8.21 \%$ vs. $25 \% ; p=0.05)$. No differences were detected in miscarriage rates, multiple pregnancy rates/ cycle and hyper stimulation syndrome incidence.

Conclusions: The step-up protocol is longer-lasting but more effective obtaining pregnancies than the stepdown in patients with unexplained infertility undergoing intrauterine insemination. This effect could be explained by lower cancellation rates due to ovarian hyper response than the step-down protocol, with no differences in ovarian hyper stimulation syndrome incidence.

Keywords: ovarian stimulation, step-up protocol, stepdown protocol, intrauterine insemination, unexplained infertility

\section{INTRODUCTION}

Unexplained infertility is defined as the lack of a cause for conceiving failure after standard infertility testing, and affects $30-50 \%$ of couples unable to conceive (Ray et al., 2012). It includes idiopathic cases, usually treated by ovarian stimulation with gonadotropins associated with intrauterine insemination (IUI) in order to increase pregnancy likelihood by rising the number of eggs available for fertilization up to 2-3 (Steures et al., 2006). Nevertheless, these strategies increase the multifollicular development risk, leading to higher incidence of multiple pregnancy and ovarian hyper stimulation syndrome (OHSS) (Sagle et al., 1991; Homburg et al., 1995; Sociedad Española de Fertilidad, 2017).
The precise mechanisms of mono/oligofollicular development goal for IUI are still unknown, making it difficult to design safe pharmacological strategies. In this context, two different controlled ovarian stimulation protocols, known as "step-up" and "step-down", were designed to avoid multifollicular growth. Both protocols are based on adapted sequential gonadotropin dosage changing to induce a more physiological ovulation, either by increasing doses in the step-up protocol or by decreasing them in the step-down. These regimens have been widely but heterogeneously evaluated in polycystic ovary syndrome (PCOS) patients, with major risk of multifollicular growth because of their elevated ovarian reserve and particularly extreme sensitivity to exogenous gonadotropins (Sagle et al., 1991; Homburg et al., 1995; Kamrava et al., 1982; Seibel et al., 1984; Polson et al., 1987; Buvat et al., 1989; Shoham et al., 1991; Dale et al., 1993; van Santbrink et al., 1995; White et al., 1996). Although both protocols have shown to be successful in reducing the number of growing follicles versus other strategies, the authors found conflicting results when comparing their efficacy on time to follicular recruitment, hormone concentrations, and resulting pregnancy rates (Mizunuma et al., 1991; van Santbrink \& Fauser, 1997; Andoh et al., 1998; Balasch et al., 2001; Christin-Maitre \& Hugues, 2003). Moreover, their potential benefits have not been evaluated in non-PCOS patients, who represent the leading cause of IUI performance.

As decreasing multifollicular growth may reduce the risk of multiple pregnancy and OHSS in all patients, testing the step-up and step-down protocols in non-PCOS may contribute to diminish the adverse events related to IUI. In this study, our aim was to compare these protocols in patients with unexplained infertility undergoing IUI.

\section{MATERIALS AND METHODS \\ Study design}

This study is a prospective randomized parallel controlled clinical trial with $1: 1$ allocation performed at Hospital del Mar, Barcelona, and designed to compare the efficacy and safety of two different gonadotropin-based ovarian stimulation protocols in unexplained infertile couples undergoing IUI. It was approved by the local Clinical Research Ethics Committee, and all patients signed informed consent to take part in. No changes to methods were conducted after the trial commencement.

ClinicalTrials.gov Identifier: NCT01376999.

\section{Participants}

Eligible individuals were women aged $18-40$ years old who had been diagnosed of unexplained infertility and planning IUI, selected for enrolment between June 2011 and February 2013 after an extended medical history record and baseline evaluation. In the first visit, patients were explained the purpose, requisites and procedures of the study, and no invasive tests were indicated before obtaining informed consents. 
Unexplained infertility was defined as constant attempt to become pregnant for 1 year before the initial fertility evaluation, with no clear cause of conceiving failure after routine infertility study procedures in our unit. In all patients, tubal permeability was demonstrated by hysterosalpingography. Ovarian function was evaluated using a basal serum determination of $\mathrm{FSH}, \mathrm{LH}$, estradiol (E2) and prolactin; only patients with basal FSH $<10 \mathrm{mUI} / \mathrm{ml}$ and normal prolactin levels and were included. Moreover, ovarian reserve was evaluated with an antimullerian hormone (AMH) determination, as well as seric inhibin $B$ levels and ultrasonographic antral follicles count (AFC). Women with oligoamenorrhea or meeting the criteria for PCOS diagnose based on Rotterdam Criteria 2004 were excluded (Rotterdam ESHRE/ASRM-Sponsored PCOS Consensus Workshop Group, 2004). Uterine integrity was evaluated by vaginal ultrasound. Cases of benign uterine pathologies and dysfunctional bleeding were excluded, as well as history of $>3$ previous cycles of IUI. Male factor was studied with at least one seminogram evaluated according to WHO criteria 2010; only patients with partners presenting $>5$ millions of motile sperm were included. Other exclusion criteria were $<20 />30$ body mass index (BMI), any chronic systemic disease, and any positive serology to HIV, HVC/HVB or syphilis.

\section{Interventions}

Step-up protocol group: Women received rFSH (Gonal pen ${ }^{\circledR}$ ) 75IU sc daily, starting on day 3 of a spontaneous cycle. Vaginal ultrasound was performed on day 7 of treatment, and the rFSH dose was increased to $150 \mathrm{IU}$ if no response was observed.

Step-down protocol group: Women started with rFSH (Gonal pen ${ }^{\circledR}$ ) 150IU sc daily from day 3 of a spontaneous cycle. Vaginal ultrasound was performed on day 5 of treatment, and the rFSH dose was decreased to $75 \mathrm{IU}$ in all cases.

In both protocols, from the respective first control visit, vaginal ultrasound was performed every 48 hours until $\geq 1$ follicle reached $\geq 18 \mathrm{~mm}$ diameter, so a single dose of rhCG (Ovitrelle pen ${ }^{\circledR}$ ) $250 \mu \mathrm{g}$ sc was given. Cycles were cancelled if $\geq 4$ follicles of $\geq 14 \mathrm{~mm}$ were observed. IUI was performed 36 hours after rhCG administration, previous semen capacitating. In both groups luteal phase was supported with progesterone (Utrogestan ${ }^{\circledR}$ ) $200 \mathrm{mg} / 24$ hours after IUI.

Figure 1 summarizes the study protocols.

\section{Outcomes}

The primary outcomes were clinical pregnancy rates; defined according to the ART terminology (Zegers-Hochschild et al., 2009). Also multiple pregnancy rates, OHSS rates and miscarriage rates were registered.

Secondary outcomes were: duration of the completed ovarian stimulation for each protocol (days), total amount of rFSH used (IU), number of growing follicles, diameter of growing follicles $(\mathrm{mm})$, serum E2 levels achieved at day of rhCG $(\mathrm{pg} / \mathrm{ml})$, and hyper response rate leading to IUI cancellation in each group of patients.

\section{Sample size}

Predefining an alfa and beta risk of 0.05 and 0.20 , respectively, in a bilateral contrast, we calculated a sample size of 75 patients in each group to find statistically significant differences $>20 \%$ in pregnancy rates between groups. A total $10 \%$ follow-up loss was accepted.

\section{Randomization}

Randomization was generated by computerization on a web-based program, then automatically exported to an excel program.

\section{Statistical analysis of results}

An unpaired Student's t-test of variance was performed when appropriate. For primary outcomes, we applied an intention-to-treat approach to get clinically relevant findings for medical practice. Data were analyzed by

\section{Step-up protocol}

No follicular growth

Menstruation day

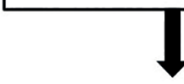

$\begin{array}{lllllllll}1 & 2 & 3 & 4 & 5 & 6 & 7 & 8 & 9\end{array}$
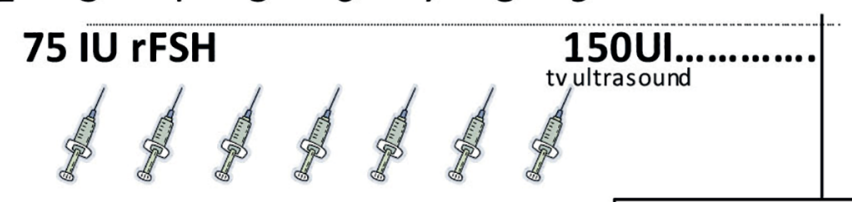

Step-down protocol

Menstruation day
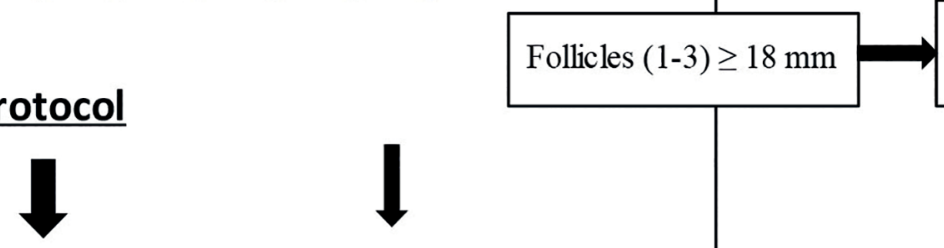

Artificial

Insemination

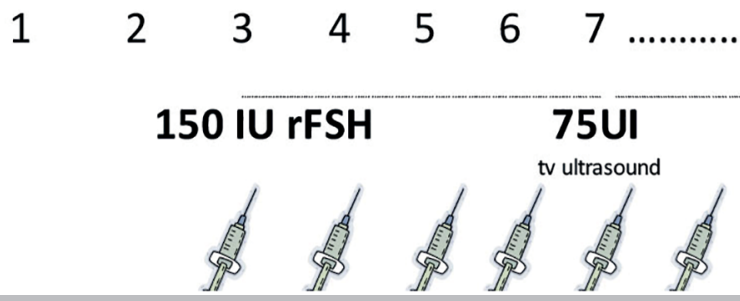

Figure 1. Step-up and Step-down ovarian stimulation protocols. 
SPSS software (18.0 version, Chicago, USA) assuming a statistically significant level of $5 \%(p<0.05)$.

\section{Cost analysis}

The financial costs of both stimulation protocols and the costs per pregnancy obtained in each group of patients were calculated as follows:

- Cost of a stimulation protocol $=$ (Cost of gonadotropins $x$ mean of the total sFSH used units) $+€ 50$ Ovitrelle as trigger medication $+€ 300$ cost of seminal preparation and in-office insemination including cannula, speculum, etc.

- Cost per pregnancy obtained $=$ (Cost of the protocol $/$ patient $\mathrm{x} \mathrm{n}^{\circ}$ of stimulated patients) / pregnancies achieved.

\section{RESULTS}

A total of 158 eligible patients with unexplained infertility were recruited. 79 were randomly allocated in the stepup group and 79 in the step-down. Finally, 73 cycles in the step-up group and 72 in the step-down were initiated and analyzed. Flow chart is shown in Figure 2.

Basal characteristics of patients were comparable between groups, as reported in Table 1.

We observed a significantly higher clinical pregnancy rate in the step-up group than in the step-down (20.5\% vs. $8.3 \%$; $p=0.037)$. Twin pregnancies showed a non-significant tendency to be higher in the step-down group than in step-up ( $16.7 \%$ vs. $6.7 \% ; p=0.5$ ). The miscarriage rate was similar between both regimens ( $13.3 \%$ vs. $16.7 \% ; p=1.0)$.
The number of intermediate grown follicles $(14-17 \mathrm{~mm}$ diameter at the time of hCG) did significantly differ between the step-up and the step-down protocols (1.48 2.26 vs. $2.32 \pm 2.40 ; p=0.019)$. Moreover the cases of ovarian hyper response were significantly higher with the stepdown protocol than with the step-up (18 vs. 6$)$, leading to a major cancellation rate $(25 \%$ vs. $8.21 \% ; p=0.005)$. When comparing the patients undergoing IUI only, without considering the cancelled cycles, we found no statistical differences regarding clinical pregnancy rates between the step-up and the step-down group (22.4\% vs. $11.1 \%$; $p=0.103$ ).

No cases of severe OHSS were documented, although 1 patient suffered a mild case in the step-up group and 3 patients in the step-down $(1.23 \%$ vs. $4.16 \% ; p=0.363)$. Those four cases had a favorable evolution and did not require medical intervention. All outcomes are presented in Table 2.

The step-up protocol financial cost was $€ 682.31$ per patient $[(€ 0.38 /$ IU Gonal-F x 874.5 IU) + €50 Ovitrelle + $€ 300$ insemination]; while the step-down protocol cost was $€ 675.47$ per patient $[(€ 0.38 /$ IU Gonal-F x 856.5 IU) + $€ 50$ Ovitrelle + €30].

The financial cost per pregnancy obtained in the stepup group was $€ 3.320 .58$ [ $(€ 682.31 \times 73$ patients $) / 15$ pregnancies achieved]; while the cost per pregnancy obtained in the step-down was $€ 8,105.64$ [( $€ 675.47 \times 72$ patients) / 6 pregnancies achieved].

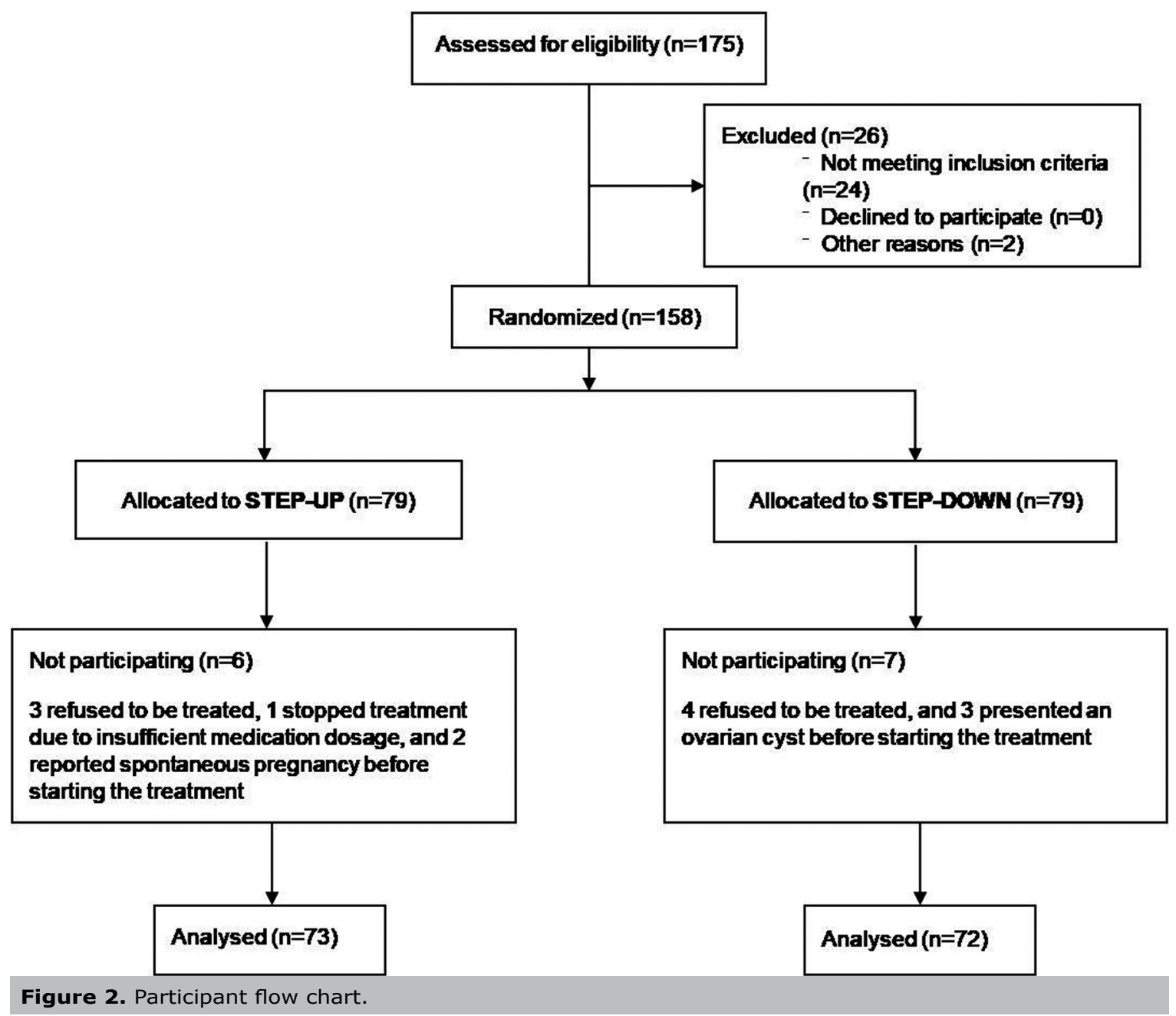


Table 1. Basal characteristics of 145 patients with unexplained infertility. Women were randomized for step-up o step-down protocol.

\begin{tabular}{|l|c|c|}
\hline & $\begin{array}{c}\text { Step-down } \\
(\mathbf{n = 7 2 )} \\
\text { (Mean } \pm \text { SD*) }\end{array}$ & $\begin{array}{c}\text { Step-up } \\
\text { (n=73) } \\
\text { (Mean } \pm \text { SD) }\end{array}$ \\
\hline Age (years) & $34.69 \pm 3.87$ & $34.73 \pm 3.81$ \\
\hline FSH $(\mathrm{mIU} / \mathrm{ml})$ & $6.79 \pm 1.57$ & $7.00 \pm 1.75$ \\
\hline LH $(\mathrm{mIU} / \mathrm{ml})$ & $6.20 \pm 2.21$ & $6.63 \pm 2.15$ \\
\hline Estradiol $(\mathrm{pg} / \mathrm{ml})$ & $48.72 \pm 23.65$ & $53.77 \pm 36.18$ \\
\hline AMH $(\mathrm{mcg} / \mathrm{L})$ & $3.32 \pm 3.20$ & $2.54 \pm 2.59$ \\
\hline Inhibin B (pg/ml) & $87.78 \pm 101.16$ & $68.61 \pm 49.58$ \\
\hline Right antral follicles & $5.68 \pm 1.99$ & $6.42 \pm 2.65$ \\
\hline Left antral follicles & $6.32 \pm 3.09$ & $6.48 \pm 3.21$ \\
\hline
\end{tabular}

*SD=standard deviation.

Both compared protocols represent similar prices per patient, but the cost per pregnancy in the Stepup group is 2.44 times lower. Therefore, we found that the Step-up protocol is not only associated to a higher clinical pregnancy rate in the study population $(20.5 \%$ vs. $8.3 \%$; $p$-value $=0.037$ ), but also remarkably cost-efficient. Given that the Step-down protocol relates with a significantly lower clinical pregnancy rate, higher cancellation rate and much higher financial cost per pregnancy, we reinforce our recommendation of using the step-up protocol in patients with unexplained infertility undergoing IUI.

\section{DISCUSSION}

This study found that the step-up protocol is more effective achieving clinical pregnancy by IUI than the stepdown in unexplained infertile couples, presenting a lower cancellation rate due to ovarian hyper response, and without differences in the assessed adverse events.

To date, there were no studies comparing the efficacy and safety of the step-up and the step-down protocols in this group of patients, but both regimens have been widely studied in PCOS patients, mainly regarding follicular growth outcomes (Mizunuma et al., 1991; van Santbrink \& Fauser, 1997; Andoh et al., 1998; Balasch et al., 2001; Christin-Maitre \& Hugues, 2003; Hugues et al., 1996). While some authors reported that the step-up protocol seems safer and resulted in more monofollicular cycles, others totally differ in their findings supporting the step-down strategy. There is also controversy about the treatment duration, rFSH needed and E2 levels achieved. The only authors also analyzing the related pregnancy rates, found no differences between the two protocols (Christin-Maitre \& Hugues, 2003). However, the important heterogeneity in the design of these studies, including different kind and doses of administered gonadotropins, could induce to contradictory conclusions. Moreover, PCOS patients are at particular higher risk of multifollicular development, so of multiple pregnancy and OHSS, than normoovulatory patients as the included in our study (Sagle et al., 1991; Homburg et al., 1995).

Although many patient-specific factors as age, AFC, high $\mathrm{AMH}$ levels, BMI and previous response to ovulation induction can influence the number of growing follicles per cycle (Checa et al., 2010; Jeon et al., 2013; Thijssen et al., 2017; Speyer et al., 2013); these baseline characteristics were comparable between study groups in our trial.

The pregnancy rates we obtained in the step-up group were superior than the reported for IUI in our media according to the last Spanish national register (Sociedad Española de Fertilidad, 2017), around $15.6 \%$ in women aged $<40$ years old and $9.9 \%$ in those $>40$. Contrarily, pregnancy rates in the step-down group were lower than expected. The higher cancellation rate in the step-down group might have influenced the pregnancy rate difference reported, favoring the step-up protocol. This difference is not found when comparing the cycles finally undergoing IUI only, which sustains our rationale and represents a relevant finding for clinical practice. Differences were neither found in AMH levels and basal AFC between the patients with cancelled cycles due to hyper response and those who underwent IUI. In ovulatory women, starting the treatment with higher rFSH doses initially recruits a major number of follicles explaining the greater multifollicular response in the step-down group, which does not seem to decrease by diminishing rFSH later in the cycle (Tan et al., 2005). Similarly, increasing rFSH dose during the step-up protocol course does not seem to rectify an initial monofollicular growth, thus not leading to hyper response (van Hooff et al., 1993; Hock et al., 1998; Khalaf et al., 2002).

The higher multifollicular developments in the stepdown group causing a $25 \%$ of cancellations are consistent with some reports from studies on PCOS patients (Andoh et al., 1998), differing from others (van Santbrink \& Fauser, 1997; Andoh et al., 1998; Balasch et al., 2001). Van Santbrink \& Fauser (1997) observed a higher monofollicular development in PCOS clomiphene-resistant patients

Table 2. Clinical results among de two study groups.

\begin{tabular}{|l|c|c|c|}
\hline & $\begin{array}{c}\text { Step-up (n=73) } \\
\text { Nositives/total, \%) }\end{array}$ & $\begin{array}{c}\text { Step-down (n=72) } \\
\text { N (positives/total, \%) }\end{array}$ & p-value \\
\hline Clinical pregnancy & $15(20.5)$ & $6(8.3)$ & 0.037 \\
\hline Twin pregnancy & $1(6.7)$ & $1(16.7)$ & 0.5 \\
\hline Miscarriages & $2(13.3)$ & $1(16.7)$ & 1.0 \\
\hline Treatment duration (days) & $8.83 \pm 4.01$ & $7.42 \pm 2.18$ & 0.001 \\
\hline Total amount of rFSH (IU) & $874.5 \pm 300.75$ & $856.5 \pm 327$ & 0.34 \\
\hline Intermediate follicles (14-17mm) & $1.48 \pm 2.26$ & $2.32 \pm 2.40$ & 0.019 \\
\hline Estradiol at day of rhCG (pg/ml) & $640.83 \pm 501.4$ & $845.31 \pm 564.565$ & 0.034 \\
\hline Hyper response. cancelled & $7(8.21)$ & $18(25)$ & 0.005 \\
\hline OHSS & $1(1.37)$ & $3(4.17)$ & 0.363 \\
\hline
\end{tabular}

$* \mathrm{~N}=$ total number. 
following the step-down protocol compared with the ones following the step-up ( $88 \%$ vs. $56 \% ; p=0.04)$. This could be attributed to their basal anovulatory condition, better responding to higher initial doses followed by a more physiological decrease of rFSH than to a stepping up approach possibly leading them to a higher number of cancellations (Koundouros, 2008). However, our study included normoovulatory women only, with better chances of initial monofollicular response to rFSH lower doses than some PCOS (Sagle et al., 1991; Homburg et al., 1995). Also, our stepup regimen resulted in a longer-lasting induction with comparable rFSH units required versus the step-down, similarly to what other authors reported (van Santbrink \& Fauser, 1997; Christin-Maitre \& Hugues, 2003).

We found no difference in multiple pregnancy rates between groups, although the sample size of this study was not specifically calculated to detect so. In contrast, a trial involving 1682 ovarian stimulated IUI cycles reported a multiple pregnancy rate of $10.5 \%$, associating the rate of multiplets to the number of follicles $>14 \mathrm{~mm}$ diameter observed the day of hCG $(3,6 \%$ if 1 follicle $>14 \mathrm{~mm}, 10 \%$ if $2,17 \%$ if 3 , and $45 \%$ if $>3 ; p=0.0001$ ) (Ghesquiere et al., 2007). These data are in agreement with the recently reported by ESHRE (European Society of Human Reproduction and Embriology) from 169.952 IUI cycles analyzed, reporting $9.5 \%$ twins in women $<40$ years old (De Geyter et al., 2018). We did not notify any case of severe OHSS, which was expected considering the limited number of growing follicles. Our OHSS incidence was similar to those previously reported (Golan et al., 1989).

One limitation of our study was the impossibility to evaluate live born rates because an important follow-up loss of cases once clinical pregnancy was confirmed and patients transferred to local hospitals.

Finally, both compared protocols represent similar prices per patient in our setting, but the cost per pregnancy in the step-up group was 2,44 times lower. Therefore, we found that the step-up protocol was not only associated to a higher clinical pregnancy rate in the study population, but also remarkably cost-efficient. In contrast, the step-down protocol related with a higher cancellation rate and much higher financial cost per pregnancy; hence we reinforce our recommendation against it in the study population.

In conclusion, this study represents the first RCT comparing the step-up versus the step-down ovarian stimulation protocol in patients with unexplained infertility undergoing IUI. In this population, the step-up protocol obtains a better pregnancy rate with a significantly lower cancellation rate than the step-down, without differences in adverse outcomes as multiple pregnancy and OHSS. The step-up group also appears to be considerably cost-efficient. Therefore, at present time, the step-up protocol should be the first choice of gonadotropin therapy for IUI cycles in patients with unexplained infertility.

Registration number:

ClinicalTrials.gov Identifier: NCT01376999

\section{Sources of funding or other support:}

none. This research did not receive any specific grant from funding agencies in the public, commercial, or notfor-profit sectors.

\section{Author contribution:}

$A R$ and MAC conceived the hypothesis of the study, established clear objectives and designed the trial. AR, MP, MGC and MAC collected the data. AR, MP, SGL and MAC performed the analysis and interpretation of the data. AR and SG wrote the article after conducting the literature examination. MP, MGC and MAC critically revised earlier drafts of the article for important intellectual content; and all authors gave final approval of the version to be submitted.

\section{CONFLICT OF INTEREST}

None

\section{Corresponding author:}

Miguel Ángel Checa

Department of Obstetrics and Gynecology

Hospital del Mar,

Consorci Parc de Salut Mar

Barcelona, Spain.

E-mail: macheca@parcdesalutmar.cat

\section{REFERENCES}

Andoh K, Mizunuma $\mathrm{H}$, Liu X, Kamijo T, Yamada K, Ibuki Y. A comparative study of fixed-dose, step-down, and low-dose step-up regimens of human menopausal gonadotropin for patients with polycystic ovary syndrome. Fertil Steril. 1998;70:840-6. PMID: 9806564 DOI: 10.1016/ S0015-0282(98)00308-2

Balasch J, Fábregues F, Creus M, Puerto B, Peñarrubia J, Vanrell JA. Follicular development and hormone concentrations following recombinant FSH administration for anovulation associated with polycystic ovarian syndrome: prospective, randomized comparison between low-dose step-up and modified step-down regimens. Hum Reprod. 2001;16:652-6. PMID: 11278212 DOI: 10.1093/humrep/16.4.652

Buvat J, Buvat-Herbaut M, Marcolin G, Dehaene JL, Verbecq $P$, Renouard $O$. Purified follicle-stimulating hormone in polycystic ovary syndrome: slow administration is safer and more effective. Fertil Steril. 1989;52:553-9. PMID: 2509248 DOI: 10.1016/S0015-0282(16)60962-7

Checa MA, Prat M, Carreras R. Antral follicle count as a predictor of hyperresponse in controlled ovarian hyperstimulation/intrauterine insemination in unexplained sterility. Fertil Steril. 2010;94:1105-7. PMID: 20045519 DOI: 10.1016/j.fertnstert.2009.10.063

Christin-Maitre S, Hugues JN; Recombinant FSH Study Group. A comparative randomized multicentric study comparing the step-up versus step-down protocol in polycystic ovary syndrome. Hum Reprod. 2003;18:1626-31. PMID: 12871872 DOI: $10.1093 /$ humrep/deg336

Dale O, Tanbo T, Lunde O, Abyholm T. Ovulation induction with low-dose follicle-stimulating hormone in women with the polycystic ovary syndrome. Acta Obstet Gynecol Scand. 1993;72:43-6. PMID: 8382432 DOI: $10.3109 / 00016349309013348$

De Geyter C, Calhaz-Jorge C, Kupka MS, Wyns C, Mocanu E, Motrenko T, Scaravelli G, Smeenk J, Vidakovic S, Goossens V; European IVF-monitoring Consortium (EIM) for the European Society of Human Reproduction and Embryology (ESHRE). ART in Europe, 2014: results generated from European registries by ESHRE: The European IVF-monitoring Consortium (EIM) for the European Society of Human Reproduction and Embryology (ESHRE). Hum Reprod. 2018;33:1586-601. PMID: 30032255 DOI: 10.1093/humrep/dey 242 
Ghesquiere SL, Castelain EG, Spiessens C, Meuleman $\mathrm{CL}$, D'Hooghe TM. Relationship between follicle number and (multiple) live birth rate after controlled ovarian hyperstimulation and intrauterine insemination. Am J Obstet Gynecol. 2007;197:589.e1-5. PMID: 18060945 DOI: 10.1016/j.ajog.2007.05.016

Golan A, Ron-el R, Herman A, Soffer Y, Weinraub Z, Caspi E. Ovarian hyperstimulation syndrome: an update review. Obstet Gynecol Surv. 1989;44:430-40. PMID: 2660037 DOI: $10.1097 / 00006254-198906000-00004$

Hock DL, Louie H, Shelden RM, Ananth CV, Kemmann E. The need to step up the gonadotropin dosage in the stimulation phase of IVF treatment predicts a poor outcome. J Assist Reprod Genet. 1998;15:427-30. PMID: 9717118 DOI: $10.1007 / B F 02744936$

Homburg R, Levy T, Ben-Rafael Z. A comparative prospective study of conventional regimen with chronic low-dose administration of follicle-stimulating hormone for anovulation associated with polycystic ovary syndrome. Fertil Steril. 1995;63:729-33. PMID: 7890055 DOI: 10.1016/ S0015-0282(16)57473-1

Hugues JN, Cédrin-Durnerin I, Avril C, Bulwa S, Hervé F, Uzan M. Sequential step-up and step-down dose regimen: an alternative method for ovulation induction with follicle-stimulating hormone in polycystic ovarian syndrome. Hum Reprod. 1996;11:2581-4. PMID: 9021354 DOI: 10.1093/oxfordjournals.humrep.a019173

Jeon YE, Jung JA, Kim HY, Seo SK, Cho S, Choi YS, Lee BS. Predictive factors for pregnancy during the first four intrauterine insemination cycles using gonadotropin. Gynecol Endocrinol. 2013;29:834-8. PMID: 23862582 DOI: $10.3109 / 09513590.2013 .808324$

Kamrava MM, Seibel MM, Berger MJ, Thompson I, Taymor ML. Reversal of persistent anovulation in polycystic ovarian disease by administration of chronic low-dose follicle-stimulating hormone. Fertil Steril. 1982;37:520-3. PMID: 6802679 DOI: $10.1016 /$ S0015-0282(16)46159-5

Khalaf Y, El-Toukhy T, Taylor A, Braude P. Increasing the gonadotrophin dose in the course of an in vitro fertilization cycle does not rectify an initial poor response. Eur J Obstet Gynecol Reprod Biol. 2002;103:146-9. PMID: 12069737 DOI: $10.1016 / S 0301-2115(02) 00036-2$

Koundouros SN. A comparison study of a novel stimulation protocol and the conventional low dose step-up and stepdown regimens in patients with polycystic ovary syndrome undergoing in vitro fertilization. Fertil Steril. 2008;90:569-75. PMID: 17880950 DOI: $10.1016 / j$.fertnstert.2007.06.080

Ministerio de Sanidad, Consumo y Bienestar Social. Sociedad Española de Fertilidad. Registro Nacional de Actividad 2017-Registro SEF. Informe estadístico de Técnicas de Reproducción Asistida. Madrid: Ministerio de Sanidad, Consumo y Bienestar Social. Sociedad Española de Fertilidad; 2017.

Mizunuma H, Takagi T, Yamada K, Andoh K, Ibuki Y, Igarashi M. Ovulation induction by step-down administration of purified urinary follicle-stimulating hormone in patients with polycystic ovarian syndrome. Fertil Steril. 1991;55:1195-6. PMID: 1903734 DOI: 10.1016/S00150282(16)54375-1
Polson DW, Mason HD, Saldahna MB, Franks S. Ovulation of a single dominant follicle during treatment with low-dose pulsatile follicle stimulating hormone in women with polycystic ovary syndrome. Clin Endocrinol (Oxf). 1987;26:205-12. PMID: 3117445 DOI: $10.1111 / \mathrm{j} .1365-$ 2265.1987.tb00778.x

Ray A, Shah A, Gudi A, Homburg R. Unexplained infertility: an update and review of practice. Reprod Biomed Online. 2012;24:591-602. PMID: 22503948 DOI: 10.1016/j. rbmo.2012.02.021

Rotterdam ESHRE/ASRM-Sponsored PCOS Consensus Workshop Group. Revised 2003 consensus on diagnostic criteria and long-term health risks related to polycystic ovary syndrome. Fertil Steril. 2004;81:19-25. PMID: 14711538 DOI: $10.1016 /$ j.fertnstert.2003.10.004

Sagle MA, Hamilton-Fairley D, Kiddy DS, Franks S. A comparative, randomized study of low-dose human menopausal gonadotropin and follicle-stimulating hormone in women with polycystic ovarian syndrome. Fertil Steril. 1991;55:56-60. PMID: 1898891 DOI: $10.1016 /$ S00150282(16)54059-X

Seibel MM, Kamrava MM, McArdle C, Taymor ML. Treatment of polycystic ovary disease with chronic low-dose follicle stimulating hormone: biochemical changes and ultrasound correlation. Int J Fertil. 1984;29:39-43. PMID: 6146583

Shoham Z, Patel A, Jacobs HS. Polycystic ovarian syndrome: safety and effectiveness of stepwise and low-dose administration of purified follicle-stimulating hormone. Fertil Steril. 1991;55:1051-6. PMID: 1903725 DOI: 10.1016/ S0015-0282(16)54351-9

Speyer BE, Abramov B, Saab W, Doshi A, Sarna U, Harper JC, Serhal P. Factors influencing the outcome of intrauterine insemination (IUI): age, clinical variables and significant thresholds. J Obstet Gynaecol. 2013;33:697-700. PMID: 24127958 DOI: 10.3109/01443615.2013.810199

Steures P, van der Steeg JW, Hompes PG, Habbema JD, Eijkemans MJ, Broekmans FJ, Verhoeve HR, Bossuyt PM, van der Veen F, Mol BW; Collaborative Effort on the Clinical Evaluation in Reproductive Medicine. Intrauterine insemination with controlled ovarian hyperstimulation versus expectant management for couples with unexplained subfertility and an intermediate prognosis: a randomised clinical trial. Lancet. 2006;368:216-21. PMID: 16844491 DOI: $10.1016 /$ S0140-6736(06)69042-9

Tan SL, Child TJ, Cheung AP, Fluker MR, Yuzpe A, Casper $\mathrm{R}$, Leung $\mathrm{P}$, Cadesky $\mathrm{K}$, Davis VJ. A randomized, double-blind, multicenter study comparing a starting dose of 100 IU or 200 IU of recombinant follicle stimulating hormone (Puregon) in women undergoing controlled ovarian hyperstimulation for IVF treatment. J Assist Reprod Genet. 2005;22:81-8. PMID: 15844733 DOI: $10.1007 /$ s10815005-1497-1

Thijssen A, Creemers A, Van der Elst W, Creemers E, Vandormael E, Dhont N, Ombelet W. Predictive value of different covariates influencing pregnancy rate following intrauterine insemination with homologous semen: a prospective cohort study. Reprod Biomed Online. 2017;34:463-72. PMID: 28285953 DOI: 10.1016/j.rbmo.2017.01.016 
van Hooff $\mathrm{MH}$, Alberda AT, Huisman GJ, Zeilmaker GH, Leerentveld RA. Doubling the human menopausal gonadotrophin dose in the course of an in-vitro fertilization treatment cycle in low responders: a randomized study. Hum Reprod. 1993;8:369-73. PMID: 8473450 DOI: 10.1093/ oxfordjournals.humrep.a138053

van Santbrink EJ, Hop WC, van Dessel TJ, de Jong FH, Fauser BC. Decremental follicle-stimulating hormone and dominant follicle development during the normal menstrual cycle. Fertil Steril. 1995;64:37-43. PMID: 7789578 DOI: 10.1016/S0015-0282(16)57652-3

van Santbrink EJ, Fauser BC. Urinary follicle-stimulating hormone for normogonadotropic clomiphene-resistant anovulatory infertility: prospective, randomized comparison between low dose step-up and step-down dose regimens. J Clin Endocrinol Metab. 1997;82:3597-602. PMID: 9360513 DOI: 10.1210/jcem.82.11.4369
White DM, Polson DW, Kiddy D, Sagle P, Watson H, GillingSmith C, Hamilton-Fairley D, Franks S. Induction of ovulation with low-dose gonadotropins in polycystic ovary syndrome: an analysis of 109 pregnancies in 225 women. J Clin Endocrinol Metab. 1996;81:3821-4. PMID: 8923819 DOI: $10.1210 /$ jcem.81.11.8923819

Zegers-Hochschild F, Adamson GD, de Mouzon J, Ishihara $\mathrm{O}$, Mansour R, Nygren $\mathrm{K}$, Sullivan $\mathrm{E}$, Vanderpoel S; International Committee for Monitoring Assisted Reproductive Technology; World Health Organization. International Committee for Monitoring Assisted Reproductive Technology (ICMART) and the World Health Organization (WHO) revised glossary of ART terminology, 2009. Fertil Steril. 2009;92:1520-4. PMID: 19828144 DOI: $10.1016 / j . f e r t n-$ stert.2009.09.009 